\title{
Donepezil did not reduce the rate of institutionalisation or disability in people with mild to moderate Alzheimer's disease
}

AD2000 Collaborative Group. Long-term donepezil treatment in 565 patients with Alzheimer's disease (AD2000): randomised double-blind trial. Lancet 2004;363:2105-15.

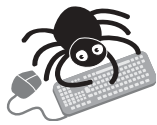

This article

contains extra text on the EBMH website

\section{What is the effect of donepezil in people with mild to moderate Alzheimer's disease?}

\section{METHODS}

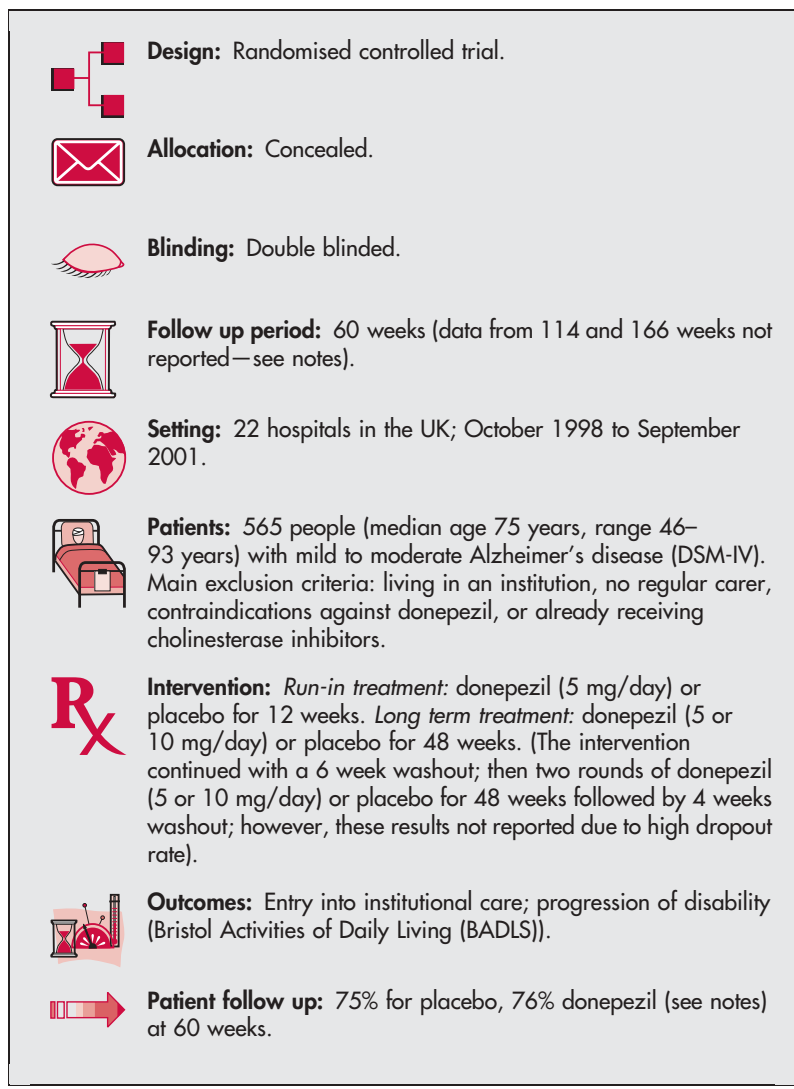

\section{MAIN RESULTS}

At 60 weeks, there were no significant differences between donepezil and placebo in institutionalisation rates or progression to disability in people with mild to moderate Alzheimer's disease (see http:// www.ebmentalhealth.com/supplemental for table). There were no significant differences in institutionalisation rates between the $10 \mathrm{mg}$ and $5 \mathrm{mg}$ donepezil groups ( $10 \mathrm{mg} v 5 \mathrm{mg}$ : $37 v 44, \mathrm{p}=0.7$ ).

\section{CONCLUSIONS}

Donepezil does not delay time to institutionalization or progression to disability in people with mild to moderate Alzheimer's.

\section{NOTES}

See http://www.ebmentalhealth.com/supplemental for notes. In addition, the AD2000 authors dispute this interpretation-see http://www.ebmentalhealth.com/supplemental for their response.

For correspondence: AD2000 Collaborative Group, University of Birmingham Clinical Trials Unit, Park Grange, Somerset Road, Birmingham B15 2RR, UK; AD2000@bham.ac.uk

Sources of funding: This study was funded by Research into Ageing, London, UK and Age Concern, London, UK.
Commentary

he superiority, typically in cognition, of donepezil, and other cholinesterase inhibitors (ChEls) to placebo has been confirmed in a systematic review. ${ }^{1}$ Meta-analysis has shown ChEls to have a modest beneficial impact on neuropsychiatric and functional outcomes (approximately $0.1 \mathrm{SD}$ ) in patients with mild to moderate $A D$ that relative to placebo. ${ }^{2}$ In a more recent report donepezil significantly improved neuropsychiatric symptoms ( $p<0.05$ for all domains of the NPI) relative to placebo in $A D$ patients. ${ }^{3} \mathrm{~A}$ meta-analysis of 16 RCTs of ChEls $(\mathrm{n}=7954)$ demonstrated that the NNT was $7(95 \% \mathrm{Cl} 6$ to 9) for stabilisation or better, $12(95 \% \mathrm{Cl} 9$ to 16) for minimal improvement or better, and $42(95 \% \mathrm{Cl} 26$ to 114$)$ for marked improvement. ${ }^{4} \mathrm{~A}$ Cochrane Review confirmed clinical efficacy of donepezil. ${ }^{5}$ Why could AD2000 not demonstrate these benefits?

In the AD2000 trial, donepezil benefit was demonstrated over the first two years of the study for both cognition $(95 \% \mathrm{Cl} 0.5$ to $1.2 \mathrm{MMSE}$ points; $p<0.0001)$ and functionality $195 \% \mathrm{Cl} 0.5$ to 1.6 BADLS points; $p<0.0001)$ despite a six week washout after 48 weeks of therapy, submaximal dosing, and a remarkable attrition rate. Can the small numbers studied in year three (life table estimates) truly negate this demonstrated efficacy and that of multiple other studies? The attrition, along with the washout phases, dosing, and a study design allowing centres to drop out in favour of going open label, raise concerns about the study results. Clinical trials with withdrawal periods indicate that withdrawal and reinitiation of CHEls may result in loss of benefit that cannot be regained. ${ }^{6}$ The washout periods in this study certainly produced a gyration of MMSE data, and may have produced less robust results and inadvertently demonstrated the expected loss of benefits associated with interrupting therapy. This is not a regimen that would be practiced clinically, and represents a substantial flaw in establishing the validity that would be required for a study to overturn the collected evidence to date. The AD2000 primary endpoint (nursing home admission) was an insensitive and overly ambitious outcome measure at an inappropriate stage (the majority of subjects were classified as having mild dementia) of disease progression for many of the participants, and is an inappropriate parameter to gauge drug efficacy. Another interpretation of this portion of the data (equally inappropriate) is that at the end of year one, before interrupting medication and before attrition, donepezil provided a non-significant RRR of $35.7 \%$ for entry to institutional care $(p=0.15)$.

Although the laudable aim was to do a large, independent, and definitive trial, this has not been achieved for a number of design related and practical reasons. In fact, however, the results of AD2000 are not qualitatively different from, and do not invalidate, previous studies. John B Standridge, MD

Associate Professor, Department of Family Medicine, University of Tennessee Health Science Center, Chattanooga, TN, USA

1 Standridge JB. Pharmacotherapeutic approaches to the treatment of Alzheimer's disease. Clin Ther 2004;26:615-30.

2 Trinh NH, Hoblyn J, Mohanty S, et al. Efficacy of cholinesterase inhibitors in the treatment of neuropsychiatric symptoms and functional impairment in Alzheimer disease: a meta-analysis. JAMA 2003;289:210-16.

3 Holmes C, Wilkinson D, Dean C, et al. The efficacy of donepezil in the treatment of neuropsychiatric symptoms in Alzheimer disease. Neurology 2004:63:214-19.

4 Lanctot KL, Herrmann N, Yau KK, et al. Efficacy and safety of cholinesterase inhibitors in Alzheimer's disease: a meta-analysis. CMAJ 2003;169:55764.

5 Birks JS, Harvey R. Donepezil for dementia due to Alzheimer's disease (Cochrane Review). In: The Cochrane Library, Issue 3. Chichester, UK: John Wiley \& Sons Ltd, 2004

6 Cummings JL. Use of cholinesterase inhibitors in clinical practice: evidencebased recommendations. Am J Geriatr Psychiatry 2003;11:131-45. 